disease, and (3) a thorough knowledge of practical optics and refraction. It is pointed out that there are ample facilities for the required instruction at the Universities of Toronto, Kingston and London, and at the Toronto Technical School. Finally, the report recommends that all who at present practise optometry should be required to pass the suggested examination within six months.

\title{
ABSTRACTS
}

\section{SYMPATHETIC OPHTHALMITIS}

(I) Meller, J. (Vienna).-On the histology of the exciting eyes in the onset of sympathetic ophthalmia after enucleation. (Ueber den histologischen Befund in sympathisierenden Augen bei Ausbruch der sympathischen Ophthalmie nach der Enucleation.) Arch. f. Ophthal.; Vol. LXXIX, Pt. I, 1914.

(1) Meller gives an account of seven cases, some of which have been published previously, in which sympathetic ophthalmia followed at varying intervals after the removal of the injured eye. The main points of the cases are as follows:

CASE 1.-Enucleation eighteen days after injury; sympathetic ophthalmia twelve days after enucleation ran a severe course. Removed eye showed septic endophthalmitis, abscess in vitreous, choroid free, infiltration in iris and ciliary body, not typical of sympathetic.

CASE 2.-Enucleation thirty days after injury; sympathetic ophthalmia twenty-seven days after enucleation ran a severe course. Histology that of a serous iritis. Uncharacteristic infiltration of iris (everywhere penetrating the pigment layer) and ciliary body. Quite small nodules of lymphocytes in choroid. Neuritis.

CASE 3.-Enucleation twenty-eight days after injury ; sympathetic ophthalmia thirty-eight days after enucleation ran a mild course with preservation of normal vision. Histology, early stage of sympathetic inflammation. Numerous choroidal nodules. Nothing characteristic in iris and ciliary body. No definite epithelioid cells. No endophthalmitis. Marked neuritis.

CASE 4.-Enucleation thirty days after injury; sympathetic ophthalmia nineteen days after enucleation ran a severe course, but final result was good. Histology, lymphocyte nodules in posterior layers of iris and ciliary body as well as the anterior part of the choroid. No epithelioid or giant cells. Slight endophthalmitis. Neuritis. 
CASE 5.-Enucleation thirty-eight days after injury; sympathetic ophthalmia three days after enucleation ran a mild course with preservation of normal vision. Histology typical with epithelioid and giant cells in iris and ciliary body, only quite small lymphocyte nodules in choroid. Slight endophthalmitis and no neuritis.

CASE 6.-Enucleation sixty-three days after injury; sympathetic ophthalmia eight days after enucleation, course of disease unknown. Histology, characteristic picture of sympathetic ophthalmia.

CASE 7.-Enucleation thirty-one days after injury; sympathetic ophthalmia four days after enucleation ran a severe course. Histology, characteristic picture of sympathetic ophthalmia.

Meller draws the following conclusions :

A sympathetic ophthalmia that makes its appearance after enucleation may be mild or severe. The degree of inflammation reached by the exciting eye bears no relation to the severity of the affection in the second eye. There would also seem to be no definite relation between the severity of the disease and the interval between the removal of the eye and the outbreak of sympathetic inflammation. When sympathetic inflammation follows the enucleation early, the exciting eye will be found in a more advanced stage of the disease than in those cases in which a longer period intervenes.

E. E. H.

\section{(2) Meller, J (Vienna).-On necrosis in sympathetic inflammation. (Ueber Nekrose bei sympathisierender Entzündung.) Arch. f. Ophthal., Vol. LXXXIX, Part ii, I9I 5.}

(2) Meller records two cases of sympathetic ophthalmia which occurred after perforating injury in the eyes of girls at intervals of three and six weeks respectively. The reports of the clinical condition need not detain us, save to notice that the final result was the worst possible: absolute blindness. Histologically there was found in the neighbourhood of the iris and ciliary body in both eyes, a large tumour composed of granulation tissue, small round cells with numerous foci of epithelioid and giant cells, some of the Langhans type. The centre part of these foci was largely composed of necrotic detritus. Vascular obliteration was also a marked feature in the sections. The retina in each case was detached, thickened, and infiltrated with inflammatory cells, while the choroid in its posterior part was grossly thickened, the foci of epithelioid and giant cells having seemed to coalesce in this region. In each optic nerve, $6.8 \mathrm{~mm}$. behind the globe, was found a focus of epithelioid cells. von Pirquet's test was negative in each case.

Meller discusses the points in comparison between sympathetic ophthalmia and uveal tuberculosis, remarking that each is frequently of an especially severe type in children. The occurrence of slight trauma is insisted on as a starting point of tuberculous iridocyclitis. 
The histological findings in his cases showed a remarkable similarity to those of advanced tuberculous disease, although it was impossible to demonstrate the tubercle bacillus. Finally, he considers that his cases are much in favour of the bacterial origin of sympathetic ophthalmia. The gross lesions are well shown in the accompanying illustrations, while there are two fine plates of the microscopical features.

R. R. JAMES.

(3) Meller, J. (Vienna).-Sympathetic type of inflammation without affection of the second eye. (Sympathisierende Entzündung ohne Erkrankung des zweiten Auges.) Arch. f. Ophthal., Vol. LXXXIX, Pt. iii, I9I 5.

(3) Meller points out the rarity of the occurrence of the typical sympathetic inflammation in a wounded eye without involvement of the second one. Fuchs, after a great number of examinations, found only two cases of this sort. In this communication, Meller gives details of two cases.

CASE 1.-A man, aged 73, had his eye injured by the fingernail of his daughter when applying a lotion in the treatment of a catarrh. The sight was lost. Twenty-five years later the sight of the fellow eye failed. When he first came under observation the right eye showed a corneal scar, $1 \mathrm{~cm}$. long, parallel to the outer and upper margin of the cornea; to which the atrophic iris was adherent. The anterior chamber was only present below. The cornea was too opaque to permit any view of the fundus. Vision was reduced to perception of light at $6 \mathrm{~m}$.; projection accurate. The left eye had a pressure of +1 , although the pupil was reduced to a pin's head size by the previous use of eserin. Vision 6/24. The diagnosis of chronic inflammatory glaucoma was followed by a successful iridectomy, and the eye remained sound, eight months later, with a pale and excavated disc. Three days after the iridectomy on the left eye an iridectomy was also performed on the right. During the performance of this second operation a fragment of lens matter escaped. The eye healed without any complication. Seven months later the patient returned, as the eye had become painful and blind. Tension was now subnormal, cornea rough and opaque, and as there was no perception of light, the eye was removed.

Histological examination showed evidence of two distinct inflammatory procèsses, the one old and confined to the cornea, iris, and superficial parts of the ciliary body, the other more recent, chiefly affecting the choroid. While the older inflammation was chiefly indicated by the formation of connective tissue membranes, the more recent one was of the typical sympathetic form with epithelioid cells and cell nests. 
CASE 2.-A man, aged 52 years, had a perforating injury of his left eye from a fragment of metal. When first seen the upper lid was penetrated, and underneath this was a wound in the sclera, $1 \mathrm{~cm}$. long, which reached the limbus in a vertical direction. There was prolapse of the iris, and the anterior chamber was deep and contained some blood. The eye was soft and perception of light was lost. A piece of iron, $1 \mathrm{~cm}$. long and $8 \mathrm{~mm}$. broad, was removed through the scleral wound with the small magnet and the prolapsed iris was cut off. The eye never quieted down and was excised a month later. The right eye remained normal.

Beside the usual inflammatory appearances that resulted from the injury, the interest of the histological examination from the point of view of the present paper chiefly centred in the area which had been directly injured by the fragment. This lay close to the papilla. The retina and choroid were here torn and their edges entangled in a layer of tissue several $\mathrm{mm}$. broad, which consisted of a thick connective tissue with remains of blood and containing several clumps of fresh infiltrate. The centre of these clumps was composed of epithelioid cells and the periphery of leucocytes. There were also occasional giant cells of the Langhans type. No tubercle bacilli could be detected, nor was any caseation present.

Meller considers that the fact that the uveal tract was unaffected, the typical inflammation being confined to the area described above, renders it doubtful whether this case should be included as of a true sympathetic type.

Meller considers that the occasional occurrence of such cases in no way opposes his theory as to the source of the infection being one that exists in the whole body, for just as in other general diseases that usually affect both eyes, one occasionally escapes, it is only reasonable to suppose that the injured eye should occasionally be the only one to sufter.

Microscope drawings of the appearances met with accompany the paper.

E. E. H.

(4) Meller, J.(Vienna).- The histology of sympathetic ophthalmia. (Zur Histologie der Ophthalmia sympathica.) Arch. $f$. Ophthal., Vol. LXXXIX., Part iii, 1916.

(4) Meller in this paper gives details of the examination of a sympathising eye in one case of, sympathetic ophthalmia. He points out that there have been published very few accounts of the pathological examination of the second eye, and that it is of considerable interest to note how far the microscopical appearances resemble those of the much more frequently examined exciter. His case was briefly as follows.-A man of 38 with penetrating injury of right eye. Four weeks later removal of traumatic cataract. 
Six months later sympathetic ophthalmia developed and the right eye was excised. Under treatment the left eye improved and regained normal vision, but relapsed three and a half years later. Improvement again followed treatment, but relapses kept occurring, until, finally, the eye became blind and painful, and had to be removed some ten years after the original injury. The usual picture of sympathetic inflammation was found in the excised eye.

Meller draws attention to some details. -1 . The share taken in the process by the different parts of the uveal tract. The iris was most aftected, the infiltration breaking through the pigment layer and spreading out behind, but, in spite of the long duration of the aftection, the anterior layer still remained as a clear brown stripe. The ciliary body showed less sign of inflammatory change and the choroid was least aflected, but all the changes were of the typical character. 2. Some conclusion as to the age of the process was to be derived from the changes in the stroma. Thus, while the cell clusters in the ciliary body and choroid were embedded in normal stroma, those in the iris lay in an altered fibrous tissue which was the result of the organization of the sympathetic infiltrate. Meller considers that this shows that during the earlier years the afiection had been confined to the iris, and had only reached the posterior parts of the uvea during the final period of the disease. 3. While he considers that the fibrous tissue layers that covered the posterior part of the iris were part of the sympathetic process itself, the membrane on the anterior surface he attributed to plastic exudation. Plastic exudation of this type is only to be found in severe or lengthy cases of the disease. 4. There was necrosis of the pupillary part of the iris. This Meller considers to be due to the cutting off of vascular supply as a consequence of the severe infiltration of the peripheral part in which the bloodvessels were particularly afiected. 5. The lengthy course of the affection is to be explained by the outbreak of fresh foci of infiltration at various intervals. A considerable period may elapse between the various relapses.

E. E. H.

(5) Shoemaker, W. A. (St. Louis).-Concerning the diagnosis of sympathetic ophthalmia. Report of a case. American Journal of Ophthal., December, I9i6.

(5) The case reported by Shoemaker, was presented to a meeting of the St. Louis Ophthalmological Society with a view to elicit the opinion of the Society. There is, unfortunately, no record of any such opinion having been given.

The question asked by the author is whether if the "lost" eye presents no symptoms of inflammation whatever, one is justified in straightway removing it on the appearance of symptoms which may or may not be referable to sympathetic disease in the fellow eye, 
especially when the cosmetic effect of the "lost" eye is better than that of a prothesis. It is Shoemaker's opinion that when the lost eye is quiet we are not justified in making a diagnosis of sympathetic ophthalmia simply because the good eye has been attacked by uveitis or neuro-retinitis. But, as showing the difficulty of acting always according to conviction in these extremely difficult circumstances, in this case Shoemaker, although unable to make a diagnosis of sympathetic either before or after the event, nevertheless excised the blind eye, in order to be on the safe side, as, indeed, most other surgeons would have done.

The case was that of a boy, aged 14 years, who had lost the sight of the right eye through a scissors injury when one year old. Vision had always been good in the left eye until three days before consulting Shoemaker, when blurring of sight came on and increased. With V.A. at $13 / 100$, there was found to be quite a severe neuro-retinitis with a few small exudates in the retina and minute haemorrhages on the disc and in the retina. The uveal tract did not seem to be involved. The blind eye had never given any discomfort or been sensitive to touch. The wound was on the limbus and involved the iris and lens. The eye was absolutely without inflammatory symptoms, somewhat smaller than the left, and cosmetically better than an artificial eye. No perception of light. Wassermann negative. The patient was then referred to Sluder who found a left hyperplastic and a right purulent sphenoiditis. Sluder, however, did not feel justified in positively ascribing the ocular condition to the sphenoidal inflammation, and the right eye was excised. Large doses of sodium salcylate were given, along with mercurial inunction. One week after the excision there was no change in the condition of the left eye. Sluder then operated on the left sphenoid. Three days later V.A. was $13 / 100$. From this time the V.A. progressively improved to $13 / 15$ about one month afterwards. The ophthalmoscopic appearances also progressively improved. Shoemaker says, "Results seem to indicate that the blind eye was not the source of the trouble, and that the sphenoiditis was. The question is, was I justified in removing the blind eye with the diagnosis in doubt?"

The microscopic examination was made by Alt and is given in detail in the article. Briefly, Alt considered that a severe infective inflammatory process must have followed the injury. This seems to have remained particularly chronic and virulent in the posterior part of the eyeball. The peculiar signs given by Fuchs as characteristic of an eye which is likely to produce sympathetic ophthalmia were altogether wanting. Alt considers it doubtful whether the optic neuritis in the fellow eye could be looked upon as being of a sympathetic character.

ERNEST THOMSON. 
(6) v. Hippel, E. (Göttingen).-On tuberculous, sympathetic and proliferating uveitis of unknown aetiology. (Ueber tuberkulöse, sympathisierende und proliferierende Uveitis unbekannter Aetiologie.) Arch. f. Ophthal., Vol. XCII, Pt. iv, I9I7.

(6) In a long and diffuse paper $\nabla$. Hippel describes the microscopical anatomy of a number of cases of chronic uveitis in which the appearances resembled those of tuberculosis. The individual descriptions contain many points of pathological interest which could not well be set out in the space of an abstract. Numerous illustrations are given in the text, and two plates accompany the paper. v. Hippel does not agree with Meller in admitting that there is always a sharp differentiation between tuberculous and sympathetic uveitis. He quotes cases bearing on this point and says that the differentiation of the two affections by the microscope is quite impossible, and is only to be made by reason of the history of a perforating injury in the latter.

$\mathrm{He}$ expresses some doubt as to whether the tubercle bacillus may not be the cause of sympathetic ophthalmia. He considers that there may be a third as yet unknown cause of uveal inflammation, of a type resembling that of the tuberculous and sympathetic forms. One of the cases described shows that there may exist a chronic choroiditis without any injury to the pigment epithelium, and, consequently, not to be seen with the ophthalmoscope. As a result there may be a toxic disturbance of the outer layers of the retina, which, however, is likely to be recovered from.

E. E. H.

(7) Poulard, Albert.-Traumatic sympathetic ophthalmia, (Ophtalmie sympathique traumatique.) Ann. d'Ocul., Vol. CLIV, December, I9I7.

(7) At a meeting of the Ophthalmological Society of Paris, in April, 1916, Poulard delivered himself of some remarks on the rarity of sympathetic ophthalmia, and upon the unnecessarily severe operation of enucleation as generally practised in the interests of the second eye. He reaffirms his position in the present paper, deplores the bad cosmetic results of enucleation as compared with the good results of partial ablation, and gives as his evidence of the rarity of the disease, that he had been discussing the matter with a layman who devoted most of his time to philanthropic work among the blind, and who knew of only one case in the present war, and that was a case following operation for traumatic cataract. Poulard himself had seen only one case, which he publishes separately, that of Lieut. D. (see No. 9). He hopes that his remarks may lead to a just appreciation of the real infrequency of the disease, and to a considerable reduction in the number of the surgical mutilations 
resorted to by the generality of ophthalmic surgeons. He does not mention the compensatory advantage of enucleation in providing material for necessary pathological study.

W. C. Souter.

\section{(8) Poulard, Albert.-Abnormal sympathetic ophthalmia. (Ophtalmie sympathique anormale.) Ann.d'Ocul., Vol. CLIV, December, 1917 .}

(8) This case is published because sympathetic ophthalmia came on four months after a preventive enucleation. Lieut. D. was wounded on the right eye by a piece of shell on April 30, 1915 . The eye was noted on May 11 as painful, of soft tension, showing a hyphaema, and, by radiography, an intra-ocular foreign body. On June 9 enucleation was done. At the end of September the sight of the left eye, which hitherto had kept perfect, began to fail, and the lieutenant, on his way to Marseilles, consulted Poulard. On October $1, \mathrm{~L} . \mathrm{V}$. was $1 / 4$; much floating vitreous opacity and very slight signs of iritis present; fundus showed peripheral choroiditis with small brownish spots or patches. Front part of globe was now searched minutely for any possible foreign body entrance wound, but none could be found; no pain or redness. On October 12, more vitreous opacity, iris now markedly affected, with pupillary exudates and synechiae; two small spots of corneal infiltration; pain trifling; tension normal; V. $=1 / 5$.

From October 12 to end of November, generally worse with relapses; signs of iridocyclitis without " keratitis punctata," but with moderate infiltration of two parts of cornea; rather more reaction; pain moderate; T.n.; gradual fall in vision. Early in December, sharper attack of iritis, with severe injection and more pain; V. almost quite gone. After eight days attack subsides. January 2, 1916, eye quiet and painless, but V. quite gone; occasional slight transitory redness; pupil moderately dilated, synechiae almost all round; colour of iris duller; no fundus view owing to pupillary exudate. July 28, 1917, eyeball small and atrophic, upper lid depressed and some ptosis; slight redness; cornea small, but iris and pupil can still be made out; surface of iris dull and covered with prominences and depressions; area of pupil retracted, occupied by whitish. patch to which iris is adherent as a complete irregularly circular synechia. Every 10-15 days slight attacks of iridocyclitis come with slight redness of globe but without pain.

In brief-wounded April 30, 1915 ; enucleation June 9, 1915, i.e., 1 month and 10 days after the wounding; L.V. intact from June 9 to end of September-a period of 4 months; loss of vision from September 30 to December 1, i.e., 2 months.

In recording this case Poulard makes no mention of the blood reaction or of the general condition of the patient, nor was the first 
eye examined with the microscope, details of all of which would require to be given before the case could be accepted as one of sympathetic ophthalmia.

W. C. Souter.

(9) Morax, V. (Paris).-Clinical and statistical notes on sympathetic ophthalmia in the Army. (Notes cliniques et statistiques sur l'ophtalmie sympathique aux armées.) Ann. d'Ocul., Vol. CLIV, December, I9I7.

(9) This valuable paper by Morax is a compilation of the findings derived from an interrogatory addressed by himself to a large number of ophthalmic surgeons doing military work in France, a list including such well-known names as Aubineau, Cantonnet, Chaillous, Chevallereau, Coutela, Dor, Dupuy-Dutemps, Frenkel, Kalt, Galezowski, Lagrange, de Lapersonne, Petit, RochonDuvigneaud, Rollet, van Schevensteen, Valude, and others. Special attention is directed to certain points, while a four-page table is given with all these facts observed in the 39 cases collected in France in the present war.

Character of the initial wound.-In all cases, except one in which sympathetic ophthalmia came on after iridocyclitis following perforation of a corneal ulcer, there had been a penetrating wound of cornea or anterior part of sclera, usually (3l cases) penetration by fragment of bullet, shrapnel or bomb, or in a small number of cases (4) accidental puncture, or in 3 cases (2 cataract, 1 iridectomy) operative interference. In a good many of the cases iris or ciliary body prolapse is noted, incarceration 14 times at least, while an intraocular foreign body was present in 10 of the 39 cases. Sympathetic ophthalmia coming on after intervention may be due to the original injury rather than to the operation, but in one contusion case the operation for traumatic cataract was followed by sympathetic. No pure contusion case had been followed by the disease, which would support the usual theory of infection and negative the anaphylactic theory of Elschnig.

Rôle of the operations practised before the appearance of the sympathetic accident.-Interventions undertaken with the object of preventing immediate infection or sympathetic infection, viz., conjunctival flaps, resection of iris, etc., or evisceration and enucleation. The accompanying table shows the number of days after the trauma when the operation was done, and the number of days after operation before sympathetic disease appeared.

All the operations except 2 ( 1 resection of iris and 1 evisceration) had been done from 15-69 days after the infecting trauma. Of the 13 cases where evisceration or enucleation was done 11 (4 serious, 7 benign cases) developed sympathetic within 1 month, one at 41 days and one at 3 months. The 41 days' case, Cantonnet's, had a partially positive Wassermann reaction, which takes away from 


\begin{tabular}{|c|c|c|c|c|c|c|}
\hline \multicolumn{5}{|c|}{ Operation. } & \multirow{2}{*}{$\begin{array}{l}\begin{array}{c}\text { No. of days after } \\
\text { trauma. }\end{array} \\
28 \text { days }\end{array}$} & \multirow{2}{*}{$\begin{array}{c}\text { No. of days elapsed } \\
\text { before sympathetic } \\
\text { appeared. }\end{array}$} \\
\hline Conjunctival flap & $\ldots$ & $\ldots$ & $\ldots$ & $\ldots$ & & \\
\hline .. & $\cdots$ & $\ldots$ & $\cdots$ & $\cdots$ & 2 months & 9 days \\
\hline ", & $\cdots$ & $\cdots$ & $\cdots$ & $\cdots$ & 1 month & ? \\
\hline " & $\cdots$ & $\cdots$ & $\ldots$ & $\ldots$ & 27 days & 2 days \\
\hline Resection of iris & $\ldots$ & $\ldots$ & $\ldots$ & $\ldots$ & 1 month & 31 days \\
\hline ,. & $\ldots$ & $\ldots$ & $\ldots$ & $\ldots$ & 24 hours & 32 days \\
\hline Ablation of anter & rior s & nent & $\ldots$ & $\ldots$ & 48 days & 3 months \\
\hline Evisceration or $\mathrm{e}$ & xent & tion & $\ldots$ & $\ldots$ & 57 days & 1 month \\
\hline ," & ,. & $\ldots$ & $\ldots$ & $\ldots$ & 4 days & 1 month \\
\hline Enucleation & $\ldots$ & $\ldots$ & $\ldots$ & $\ldots$ & 32 days & 12 days \\
\hline , & $\ldots$ & $\ldots$ & $\ldots$ & $\ldots$ & 14 days & 22 days \\
\hline ." & $\ldots$ & $\ldots$ & $\ldots$ & $\ldots$ & $15-20$ days & 1 month \\
\hline ." & $\cdots$ & ... & $\cdots$ & $\cdots$ & 58 days & 2 days \\
\hline ", & ... & ... & $\ldots$ & $\ldots$ & 33 days & 10 days \\
\hline ." & ... & $\ldots$ & $\ldots$ & $\ldots$ & 39 days & 16 days \\
\hline ". & $\ldots$ & $\cdots$ & $\ldots$ & ... & 69 days & 41 days \\
\hline .. & ... & ... & $\ldots$ & $\ldots$ & 46|days & 3 days \\
\hline , & ... & $\ldots$ & ... & $\ldots$ & 45 days & 17 days \\
\hline ." & $\cdots$ & $\cdots$ & $\cdots$ & $\ldots$ & 40 days & 3 months \\
\hline ". & $\ldots$ & $\ldots$ & $\ldots$ & $\ldots$ & 31 days & 2 days \\
\hline
\end{tabular}

the value of the case, while the enucleated eye was apparently not examined microscopically. The man was aged 36 , on January 8 , 1916, an intra-ocular f.b., traumatic cataract-defective projection; May 15 , cataract extracted, V. with $+11 \mathrm{D} . \mathrm{Sph} .=0 \cdot 1$. On September 4, iridocyclitis, enucleation that day, piece of steel found in the ciliary body. On December 15, 1916 (three months and eleven days after enucleation and eleven months after the trauma), right eye aflected, 1-2 synechiae, slight keratitis punctata and ciliary injection, fundus normal, $\mathrm{V} .=0.9$. fell to $1 / 50$, then up to 0.4 on September 25, 1917 ; still slightly red, urine normal, Wassermann as stated. 
The other (three months) case is that of Poulard's, Lieut. D., noticed separately (see No. 9), where the evolution of the sympathetic disease is so different from the classical that Morax doubts the true nature of this case, where also the globe was not examined microscopically.

Period elapsed between the trauma and the appearance of objective signs of sympathetic disease.-Essentially variable, it has a minimum of fifteen days and a maximum of many, even twenty-five, years if one can believe some published cases where anatomical proof is wanting. Of the 39 cases there were :

Three where latent period did not exceed 15-20 days, and one case in which it lasted for $7 \frac{1}{2}$ months.

One has to fear sympathetic in the first three months, especially in the second month, after the third month it is exceptional. One rule emerging is that excision of the injured eye carried out within the first fortnight, will assuredly prevent the development of sympathetic ophthalmia. Morax agrees with Kalt that evisceration of the globe ought to be rejected, and Morax would add, because, done even four days after the trauma, it failed to prevent sympathetic in Kalt's case.

Clinical Characters of the sympathetic disease.-An analysis of the signs and symptoms in the cases does not allow of a prognostication of the disease in a particular case. The eye generally keeps irritable, dreads the light and is tender, but a number of eyes enucleated in that condition fail to show the characteristic uveal changes of the disease and, therefore, are not dangerous. Of the 39 cases, 31 had in the second eye the characters of an iridocyclitis or an iridochoroiditis, and 8 had those of oedematous neuritis, papillitis, sympathetic optic neuritis with choroiditis. The tension varies a great deal.

Evolution- and End-Result.-Evolution is capricious, a cure may occur in some weeks or take a whole year; great destruction of globe may ensue with lowered or increased tension or atrophy. What struck Morax most was the predominance of benign cases.

Blindness, or practical blindness in 12 cases.

Vision $1 / 10$ in one case.

Suicide in one case, i.e., 14 serious cases in 39.

Vision of 5/10-10/10 in 20 cases.

Vision of $3 / 10-4 / 10$ in five cases, i.e., 25 cases of favourable ending.

Conclusions.-In the war period de Lapersonne had seen one military and two civil cases, Sexe one military and two civil, Sourdille no case in more than 3,000 military wounded, but five in civil practice, three of which ended in blindness.

At the Lariboisière Ophthalmic Centre, from September, 1914, to November 23,1917 , there had been seen 6,265 military cases, with 
only one sympathetic, and 23,832 civil cases, with five cases of the disease, of which one ended in blindness, three in full vision, and one in 5/10 vision - thanks to mercurial injections and novarsenobenzol intravenously and enucleation. All 5 cases had the first eye examined microscopically and the characteristic picture confirmed, one case of injury with copper fragment developing sympathetic 25 months after the injury.

W. C. Souter.

\section{BOOK NOTICE}

Atlas d'Ophtalmoscopie de Guerre. By Prof. Félix LAGRange, Bordeaux. Text in French and English. IOO plates, 20 of which are coloured. Paris : Masson \& Co. 1918.

This atlas of ophthalmoscopic drawings forms an admirable supplement to Prof. Lagrange's book in the "Horizon" series, which has been translated into English under the titles "Fractures of the Orbit and Injuries to the Eye in War." Both book and atlas are the only works of this nature available to ophthalmologists of the allied nations. A more elaborate, but less comprehensive, treatise on war injuries of the eye, with ophthalmoscopic and other plates, is being published in expensive fasciculi in Germany. The author is von Szili, of Freiburg-im-Breisgau. Needless to remark, it can only be obtained with great difficulty.*

Prof. Lagrange's atlas is preceded by an introduction, which gives an epitome of the chief results of his observations, already recorded in greater detail in his earlier book. The plates are classified in six categories : (1) Lesions of the deep membranes, retina, and choroid, produced by concussion; (2) lesions of the optic foramen by injury to the frontal region and radiating fracture of the roof of the orbit ; (3) macular and paramacular lesions due to concussion of the facial bones without direct injury to the orbit ; (4) macular and paramacular lesions by concussion combined with peripheral lesions due to actual contact, caused by a missile passing through the face and fracturing the orbit ; (5) lesions of the deep membranes by missiles entering or traversing the orbit behind the globe without actually touching the eyeball; (6) lesions of the deep membranes by direct or indirect contusions of the eyeball itself.

* There is an excellent review of the first part of this work in the July number of the Medical Supplement to the Daily Review of the Foreign Press. A review of the second part will appear in the September number of the same publication, which can now be obtained without restriction from H.M. Stationery Office, 